\title{
Assessment of Cadmium \& Chromium stress on growth, Physiology and metal uptake using Mirabilis jalapa
}

\section{S.A. SHAHANAZ BEGUM, THARAKESWAR YADAMARI, KALYAN YAKKALA, SREEVANI PARVATHAREDDY and RAMAKRISHNA NAIDU GURIJALA *}

\author{
Department of Environmental Sciences, Sri Venkateswara University, Tirupati, India.
}

http://dx.doi.org/10.12944/CWE.10.1.26

(Received: March 09, 2015; Accepted: April 11, 2015)

\begin{abstract}
Phytoextraction potential of Mirabilis jalapa, with tuberous root having high ecological adoptability was studied in the present work. Different levels of cadmium and chromium stress on growth, physiology and metal uptake were studied using pot experiments. The experiment comprised of 5 dosages of cadmium and chromium with different test concentrations (TC) viz, TC1(0), TC2(25), TC3(50), TC4(75) and TC5(100) ppm, for the period of 45 days. Growth, physiological parameters and metal accumulation were estimated at 15 days intervals in root and shoot of Mirabilis jalapa. The shoot biomass of Mirabilis jalapa shown no significant reduction in both cadmium and chromium treatments of soil whereas, root biomass and physiological parameters like chlorophyll a, chlorophyll $\mathrm{b}$ and carotenoids were significantly reduced and shown inhibitory effect. The maximum uptake of cadmium by root and shoot was $36.2 \mathrm{mg} / \mathrm{kg}$ and $48.62 \mathrm{mg} / \mathrm{kg}$ in TC4 soils on day 45 . The maximum uptake of chromium by root and shoot was $34.8 \mathrm{mg} / \mathrm{kg}$ and $23.5 \mathrm{mg} / \mathrm{kg}$ in TC4 soils on day 45 . There is no inhibitory effect shown on metal uptake as it increased with increasing the dosage of heavy metals in soils. Bioconcentration factor (BCF) and Translocation factor (TF) were $>1$ in cadmium contaminated soils, where as in chromium contaminated soils $B C F>1$ but $T F<1$. Over all the present study can be concluded that Mirabilis jalapa could be promising accumulator and most suitable for the remediation of cadmium and chromium contaminated soils.
\end{abstract}

Key words: Mirabilis Jalapa, biomass, metal stress, bioaccumulation.

\section{INTRODUCTION}

The development of industrialization and anthropogenic activities led to an increased accumulation of heavy metals, which results in contamination of soil'. Generally, heavy metals are not biodegradable and therefore can sustain for longer time in environmental segments. Due to this bioaccumulative nature heavy metals may alter the food chain and cause various toxic effects on plants, humans and animals. In environment, the most common toxic metals are cadium, lead, mercury, arsenic, chromium and copper ${ }^{2}$. Chromium normally exists in two oxidation states in soils in which chromium (VI) is highly toxic to plants and animals in high doses and is responsible for inducing cancer and teratism, resulting liver and kidney damage.
In environment cadmium can be easily uptake by organisms ${ }^{3}$. Cadmium and chromium were found to be highly transportable in soil-plant system ${ }^{4}$. Therefore, remediation of lands polluted with toxic heavy metals is very essential for environmental conservation. Remediation could be done by many different technologies, however these procedure are laborious and costly ${ }^{5}$. Phtoremediation has been used as an effective technique for extraction of heavy metals in soil in which selected plant species is utilized for the absorption of heavy metals. Phtoremediation method is one of the most effective, simple, economical and eco-friendly ${ }^{6}$. Some plant species are endemic to metallic-ferrous soil and can tolerate greater than the used amount of heavy metal or other compounds. Extraction of heavy metals using plants in contaminated soils was a very old practice 
since 300 years, since plants have the capacity to extract heavy metals in higher concentration which are referred to a hyper accumulator ${ }^{7,8}$. Hence for the progress of phytoremediation, tracing out of new hyper accumulators which can overcome limitations like slow growth rate, less resistance and poor competitiveness with native plants which can survive in unfavourable conditions are required ${ }^{9}$ At present, Phytoremediation technologies like phytoextraction, phytofiltration, phytostabilization, phytovolatilization and phytodegradation are being adopted ${ }^{10}$. Phytoextraction was found to be best method for the accumulation and translocation of heavy metals from root to shoot and remediate soil without damaging the soil composition and fertility ${ }^{11}$. Phytoextraction could benefit in many ways like restoring soil fertility and minimizing leaching. Most of the research on phytoremediation was based on pot experiments and hydroponic culture, and very few studies evaluated the phytoextraction potential of hyper accumulators under field trials ${ }^{12}$. This research was designed with the objectives to analyse the cadmium and chromium accumulation and translocation from the contaminated soils. The aim of this work was (i) to analyse the growth performance of plant (ii) to evaluate the potential of selected plant species for the accumulation of heavy metal in different concentrations of metal amended soils along with the physico chemical parameters of soils (iii) to study the accumulation of cadmium and chromium in roots, shoots of the plant (iv) to compare the bioaccumulation and translocation factor of cadmium and chromium in selected plant species.

\section{MATERIALS AND METHODS}

An investigation was planned to identify the uptake of cadmium and chromium from contaminated soils by Mirabilis jalapa (figure (1). The plant species should possess high ecological adoptability like fast propagation, large shoot dry matter, high metal tolerance, high bioavailability, short life cycle and wide distribution.

\section{Phytoextraction experiment}

A green house study was carried out in an artificially amended sandy soil with Cadmium and Chromium using different concentrations $(0,25,50,75$ and 100ppm). Some selected soil characteristics as follows: $\mathrm{PH} 8.02$, EC0.116ms, Organic carbon $0.41 \%$, and total cadmium and chromium concentrations $2.29 \mathrm{mg} / \mathrm{kg}$ and $2.5 \mathrm{mg} / \mathrm{kg}$ respectively, available cadmium and chromium concentrations $0.57 \mathrm{mg} / \mathrm{kg}$ \& $0.6 \mathrm{mg} / \mathrm{kg}$ respectively.

Pot culture experiments were conducted using garden soil. Air dried soil of $5 \mathrm{~kg}$ transferred into each pot after mixing with salts $\mathrm{CdCl} 2.5 \mathrm{H} 2 \mathrm{O}$ and $\mathrm{K} 2 \mathrm{Cr} 2 \mathrm{O} 7$. The known concentrations of salts were mixed with air dried soil filled pots and left for stabilization for 2 days. Three replicates of each treatment were considered. To maintain same conditions for all the plants, no additional light supplied and grown under natural conditions. During the course of study no artificial fertilizers were added to improve the growth and accumulation of heavy metals.

\section{Growth performance \& Physiological study}

The growth studies of individual plants were grown under similar conditions and 9 plants for each concentration were harvested a time interval of 15 days from 0 to 45 days without destruction of roots. Plant height $(\mathrm{cm})$ was measured from root leaves to the top the plant from each pot. The root and shoot of plants were dried in hot air oven at $650 \mathrm{C}$ for 72 hours and for every 15 days shoot and root length $(\mathrm{cm})$ and dry matter $(\mathrm{g})$ of the sample (root \& shoot) were recorded. Chlorophyll a, chlorophyll $\mathrm{b}$ and carotenoids of the leaves in the test species were measured on all the harvest days. $0.5 \mathrm{~g}$ of fresh material was weighed accurately ground to a fine pulp using a mortar and pestle with the addition of

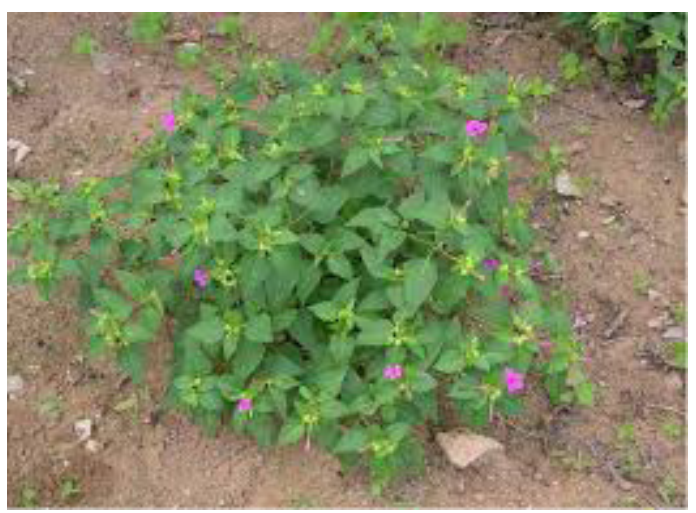

Fig. 1: Schematic diagram of Mirabilis jalapa 
$80 \%$ acetone, centrifuged and the clear supernatant was transferred to a $50 \mathrm{ml}$ of volumetric flask. This process was repeated until the residue turns to colorless and the entire solution was made up to the mark with $80 \%$ acetone to read the values in UV-VS Spectrophotometer ${ }^{13}$.

\section{Metal analysis}

The oven dried ground plant materials $0.5 \mathrm{gm}$ was accurately weighed and digested for the determination of metals using Kjeldahl flask and digested slowly using mixed acid digestion procedure ${ }^{13}$ with nitric acid (HNO3) and perchloric acid $(\mathrm{HClO} 4)$ mixture $(2: 1)$ in a closed system. The digest was heated on a hot plate until it became clear and then it was allowed to cool and filtered through a whattman filter paper. The filtrate was collected in a $50 \mathrm{ml}$ volumetric flask and diluted up to the mark with distilled water. Then the filtrate was used for the analysis of metals cadmium and chromium in sample solutions were quantified using Atomic Absorption Spectrophotometer and results were expressed in triplicates.

Total cadmium and chromium content of soil was determined by mixed acid digestion procedure and the available metal i.e., Acetic acid $(2.5 \% \mathrm{~m}$ $1: 1)$ extractable metal were determined by Atomic Absorption Spectrophotometer.

\section{Calculation of Bioconcetration and Translocation factors \\ Bioconcetration factor (BCF)}

Bioconcentration factor provides an index of the ability of the plant to accumulate a particular metal with respect to its concentration in the soil substrate. It is a ratio of the heavy metal concentration in the plant tissue (root, shoot) to that in soil. It is evaluated as follows ${ }^{14}$.

$$
\mathrm{BCF}=\frac{(\text { Metal) plant tissue }}{\text { Metal) soil }}
$$

\section{Translocation factor (TF)}

Translocation factor indicates the ability of the plant to translocate the metals from root to shoot at different concentrations. It is a ratio of concentration of the heavy metal in shots to that in its roots. It is calculated as follows ${ }^{15}$.

$$
T F=\frac{\text { (Metal) shoot }}{\text { (Metal) root }}
$$

The translocation property describe that the content of heavy metals accumulated in shoots of a plants should be higher than those in its roots i.e., TF>1 to be considered as a accumulator plant where as the ratios are invariably $<1$ is non accumulators $^{16}$.

\section{Statistical Analysis}

Average data uptake, transfer coefficient were submitted for statistical analysis. Differences in heavy metal concentrations among different parts of the plant species detected using Two-way ANOVA. A significance level of $(p<0.05)$ was used throughout the study. All statistical analyses were performed using STATISTICA (Version 7), MSEXCEL (Microsoft office 2012) and GrphPad Prism (Version 5).

\section{RESULTS AND DISCUSSION}

\section{Effect of cadmium stress on plant growth and physiology}

Toxic symptoms were not observed in any test concentrations during process of study. There was no significant reduction identified in shoot length and root dry matter compared to control. The mean values have increased showing no inhibitory effect with increases soil cadmium on all harvest days figure 2(a) and 2(b). The maximum shoot length and shoot dry matter were $37.5 \mathrm{~cm}$ and $3 \mathrm{mg} / \mathrm{kg}$ in TC4 soils on day 45 respectively. However the root length and root dry matter were significantly reduced in TC4 soils. The maximum reduction was observed on day 45 figure 2(a) and 2(b). The mean values have decreased shown that inhibitory effect on root length and root dry matter with increased in soil cadmium which is proved in the earlier reports.

As shown in figure 3(a) to 3(c). Same trend observed in physiological parameters. The mean values of leaf pigments were decreased with the increased of soil cadmium which was similar to previous studies (17). The maximum reduction in leaf pigments were $0.54 \mathrm{mg} / \mathrm{g}, 0.35 \mathrm{mg} / \mathrm{g}$ and $0.23 \mathrm{mg} / \mathrm{g}$ on day 45 in TC4 soils respectively.

\section{Effect of chromium stress on plant growth and physiology}

Root system of the plant shown significant difference relative to control. Root length and root dry matter were decreased as the dosages of chromium 
increased from 25 to $100 \mathrm{ppm}$. The tallest plants were found in control pots Figure 4(a) and 4(b). The maximum reduction in root length and root dry matter observed in TC4 soils on day 45 . Same trend observed in shoot system of the plant figure 4(a) and 4(b). In shoot system, Shoot length and shoot dry matter were increased as the dosages of Chromium increased in test concentrationsTC1 to TC4. The mean values have increased shown no inhibitory effect on shoot system with increased in soil chromium.

As shown in figure $5(\mathrm{a})$ to $5(\mathrm{c})$ total chlorophyll and carotenoid values were affected, which was similar to some previous studies ${ }^{18}$. The maximum reduction in chlorophyll a, chlorophyll b and carotenoids were $0.4 \mathrm{mg} / \mathrm{g}, 0.28 \mathrm{mg} / \mathrm{g}$ and $0.12 \mathrm{mg} / \mathrm{g}$ on day 45 in TC4soils respectively. The mean values have decreased shown that inhibitory effect on physiological parameters of test concentrations.

\section{Cadmium uptake by Mirabilis jalapa}

As shown in Table (1) and Figure 6(a) to 6 (c) the maximum accumulation by roots and shoots were $36.2 \mathrm{mg} / \mathrm{kg} \& 48.62 \mathrm{mg} / \mathrm{kg}$ in TC4 soils on day 45 . The mean values have increased with increased soil cadmium on all harvest days and shown no significant reduction, relative to control. Accumulation of cadmium was found higher in shoots rather than in shoot which indicates that cadmium is effectively translocated to shoot.

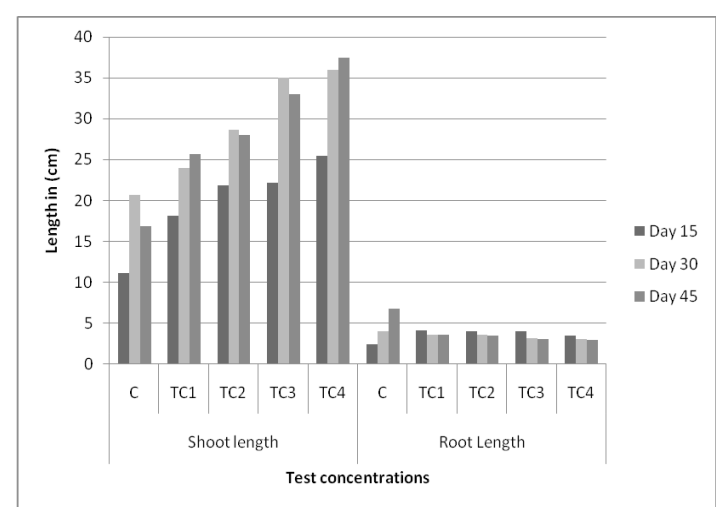

Fig. 2(a): Plant length in different concentrations on different harvest days in cadmium contaminated soil

\section{Chromium uptake by Mirabilis jalapa}

The maximum accumulation by roots and shoots were $34.8 \mathrm{mg} / \mathrm{kg}$ \& $23.5 \mathrm{mg} / \mathrm{kg}$ in TC4 soils on day 45 as shown in Table (2) and Figure 7(a) to 7(c). Accumulation of chromium was found higher in root rather than in shoot. The accumulation difference of chromium among the root and shoot was marginal. The possible reason might be that there were some other physiological reasons responsible for this phenomenon. The mean values have increased with increased soil chromium on all harvest days and shown no significant reduction, relative to control.

\section{Biological concentration factor \& Translocation factor in cadmium}

As shown in Table (3) in cadmium, the maximum BCF of shoot and root were 2.15 and 1.60 in TC4 on day 45 respectively. The BCF values in experiment increased with increased soil cadmium concentrations and all of them higher than 1.0 suggesting that Mirabilis jalapa has stable feature of cadmium accumulation. The BCF of root and shoot has increased with time showing that the plant is extracting more metal. The increase in BCF with time was positive and it is proved in earlier reports (19). Translocation values in the experiment were found to be $1.25-1.37$ respectively. The overall results shows that the maximum TF observed in TC4 on day 45. Translocation values were found to be higher than 1.0 in different test concentrations on different harvest days indicates the ability of cadmium translocation from roots to shoots.

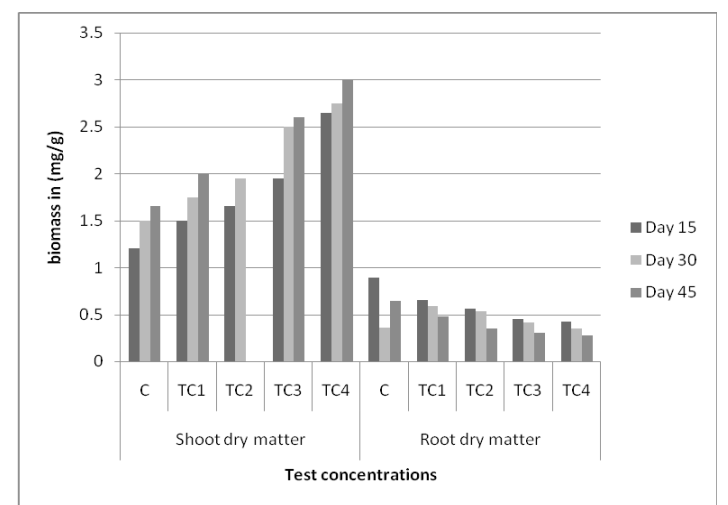

Fig. 2(b): Plant dry weight in different concentrations on different harvest days in cadmium contaminated soils 


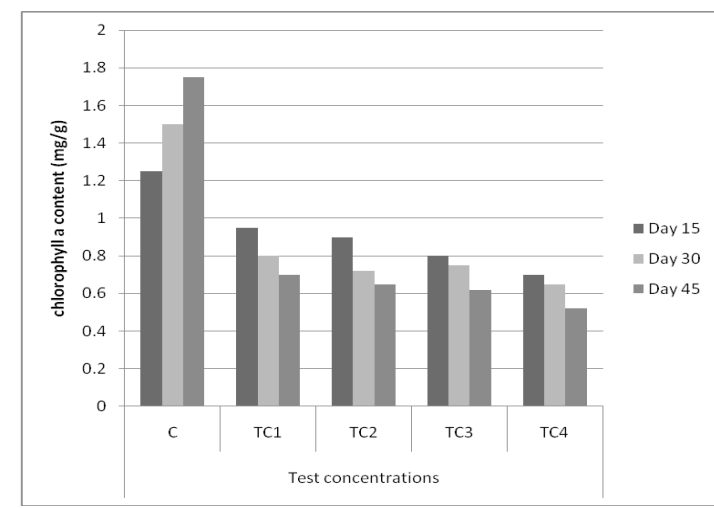

Fig. 3(a): Chlorophyll a content in different concentrations at different harvests $(\mathrm{mg} / \mathrm{g})$ in cadmium contaminated soils

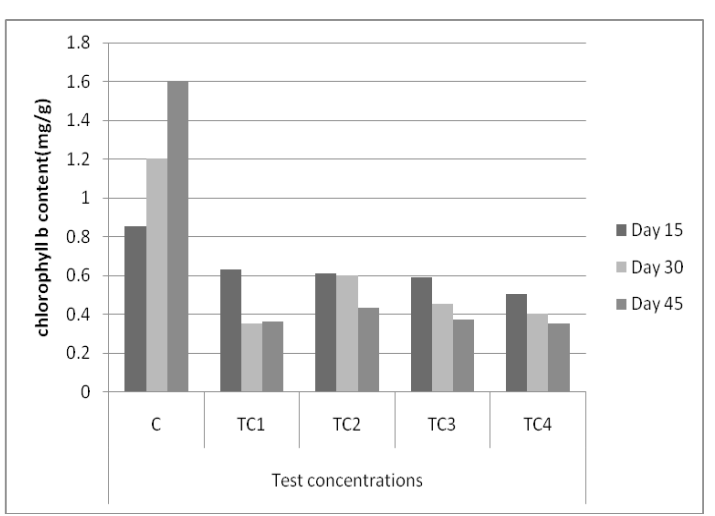

Fig. 3(b): Chlorophyll b content in different concentrations at different harvests $(\mathrm{mg} / \mathrm{g})$ in cadmium contaminated soils

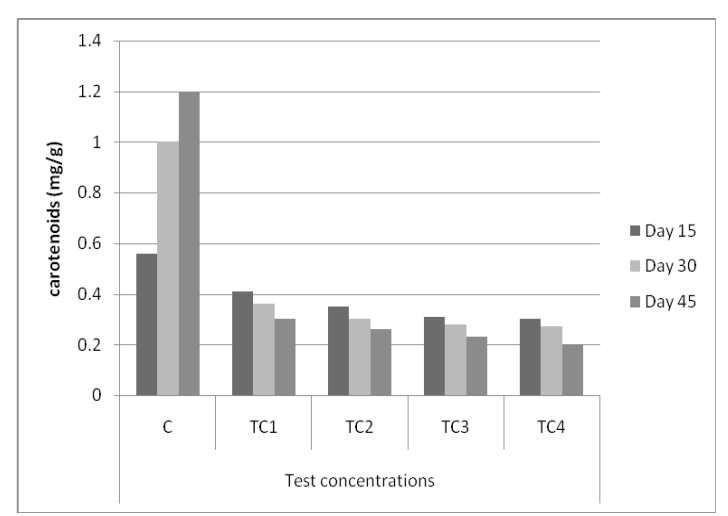

Fig. 3(c): Carotenoids content in different concentrations at different harvests $(\mathrm{mg} / \mathrm{g})$ in cadmium contaminated soils
Biological concentration factor \& Translocation factor in Chromium

As shown in Table (3) in chromium, the maximum BCF of shoot and root were $2.08 \& 1.68$ observed in TC4 on day45 respectively. All of them higher than 1.0 suggesting that Mirabilis jalapa has stable feature of chromium accumulation. The BCF of root and shoot has increased with time showing that the plant is extracting more metal. The increase in BCF with time was positive and it is proved in earlier reports.

Translocation values in the experiment were 0.76-0.81. The maximum TF observed in TC4 on day 45 . All of them lower than 1.0 in different test

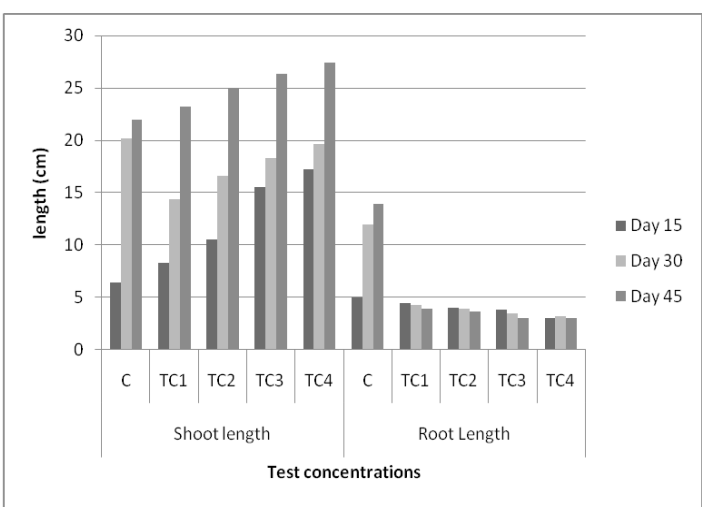

Fig. 4(a): Plant length in different concentrations on different harvest days in chromium contaminated soils

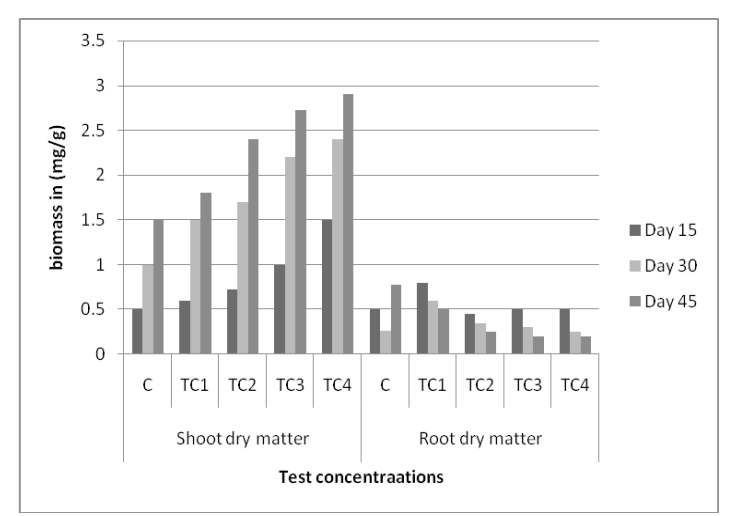

Fig. 4(b): Plant dry wt in different concentrations on different harvest days in chromium contaminated soils 


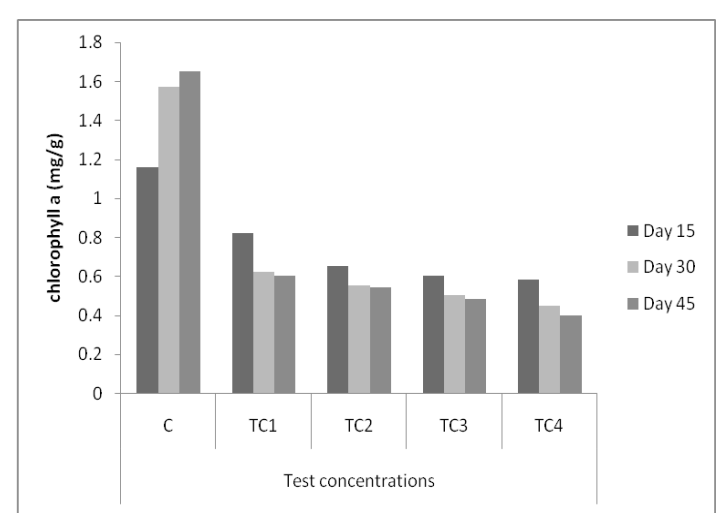

Fig. 5(a): Chlorophyll a content in different concentrations at different harvests $(\mathrm{mg} / \mathrm{g})$ in chromium contaminated soils

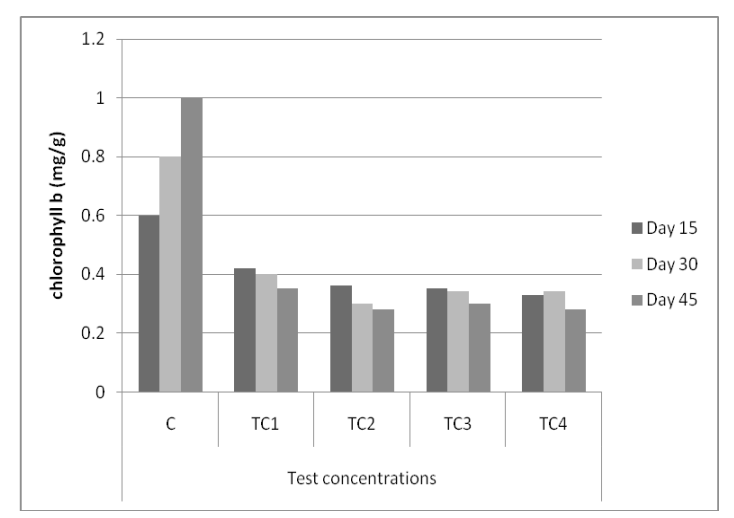

Fig. 5(b): Chlorophyll b content in different concentrations at different harvests $(\mathrm{mg} / \mathrm{g})$ in chromium contaminated soils

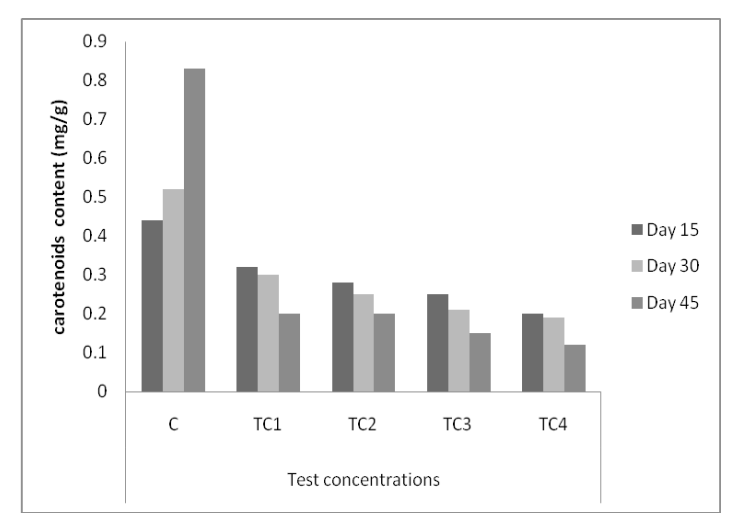

Fig. 5(c): Carotenoids content in different concentrations at different harvests $(\mathrm{mg} / \mathrm{g})$ in chromium contaminated soils

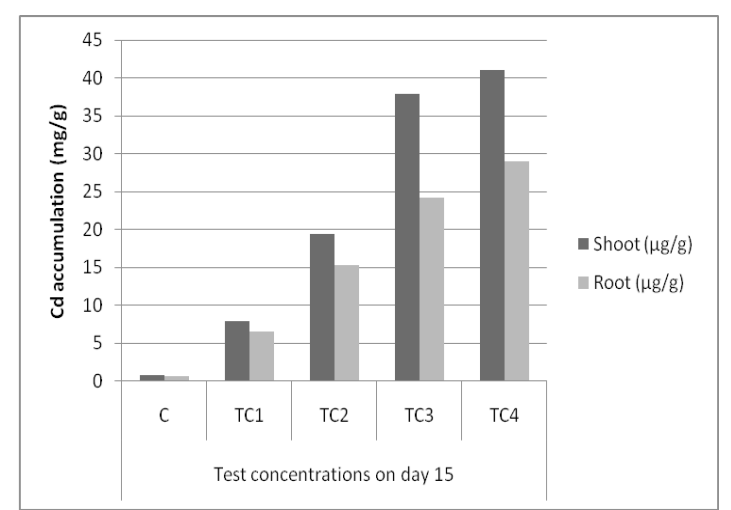

Fig. 6(a): Cadmium accumulations of shoot and root in different concentrations on day -

15

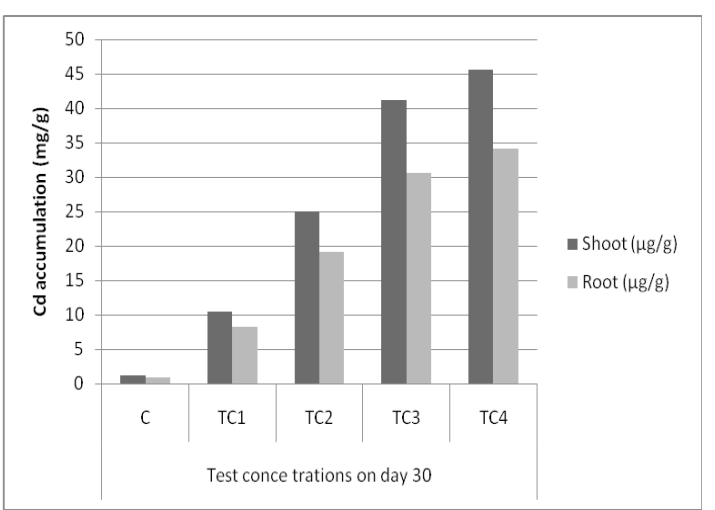

Fig. 6(b): Cadmium accumulations of shoot and root in different concentrations on day 30

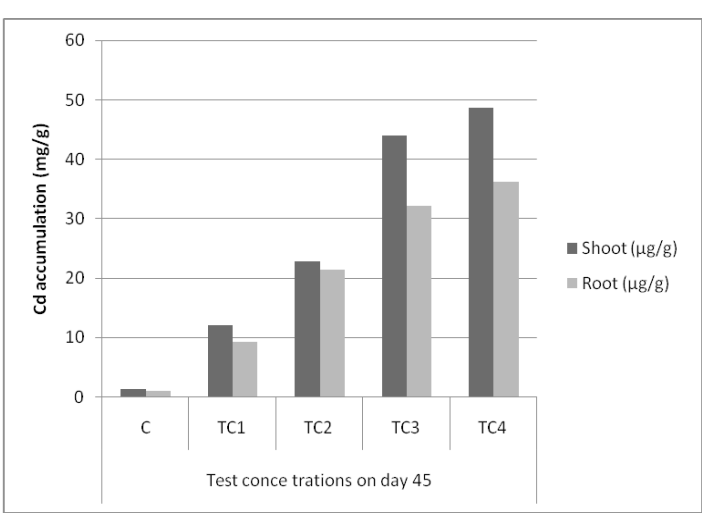

Fig. 6(c): Cadmium accumulations of shoot and root in different concentrations on day - 
concentrations on different harvest days indicates the poor ability of chromium translocation from roots to shoots.

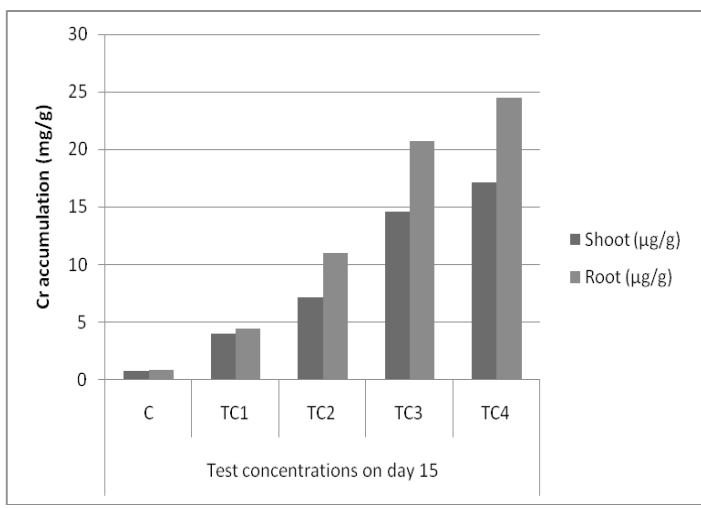

Fig. 7(a): Chromium accumulations of shoot and root in different concentrations on day 15

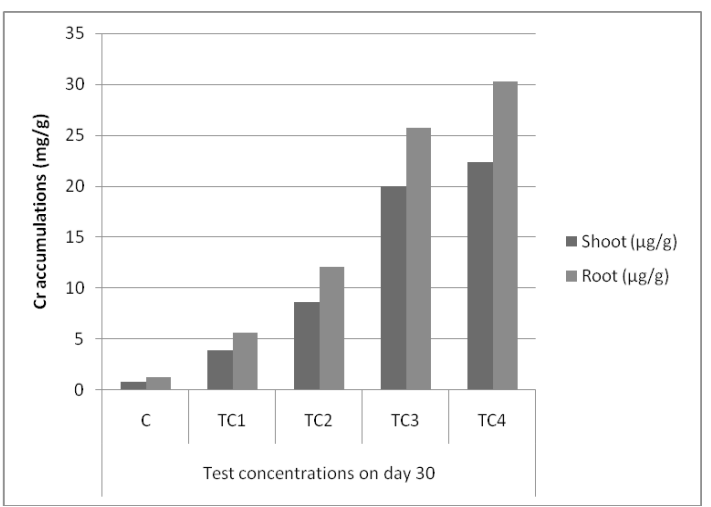

Fig. 7(b): Chromium accumulations of shoot and root in different concentrations on day 30

\section{CONCLUSION}

In the study, cadmium and chromium concentrations were significantly increased in shoot and root with increased dosage in all test concentrations. In pot studies, the test plant species Mirabilis jalapa shown a positive response for its accumulation. The plant tolerance for cadmium and chromium was evident in form of increase in shoot height and shoot dry matter of the plant. However, with increase in cadmium and chromium concentration in soils, root dry mater was considerably reduced and in the process, toxic symptoms were not identified. Whereas, accumulation of cadmium and chromium in Mirabilis jalapa induces stress and causes chlorophyll loss. The overall result have shown that the metal uptake could affect the chlorophyll a, chlorophyll b and carotenoids contents as it reduced with increase in metal exposures and time and this may be due to heavy metal stress. Overall, the mean

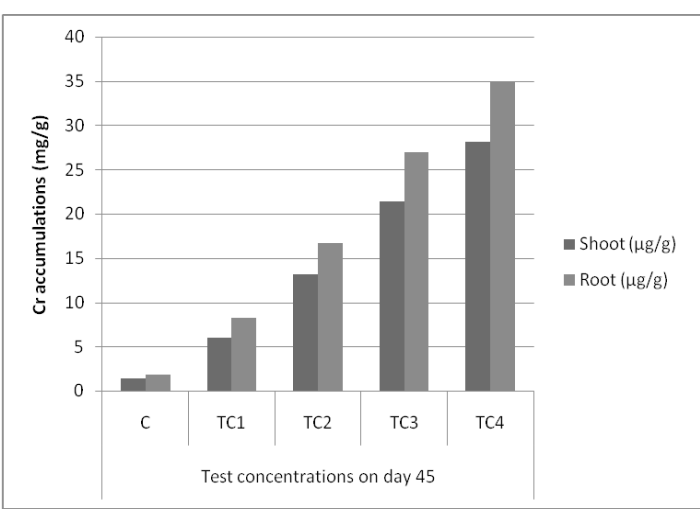

Fig. 7(c): Chromium accumulations of shoot and root in different concentrations on day 45

Table 1: Cadmium up take with varying cadmium concentrations on different harvest days

\begin{tabular}{|c|c|c|c|c|c|c|c|}
\hline \multirow{3}{*}{\multicolumn{2}{|c|}{$\begin{array}{l}\text { Cadmium } \\
\text { accumulation } \\
\text { in soils }\end{array}$}} & \multicolumn{6}{|c|}{ Harvest Days } \\
\hline & & \multicolumn{2}{|c|}{15 days } & \multicolumn{2}{|c|}{30 days } & \multicolumn{2}{|c|}{45 days } \\
\hline & & $\overline{\text { root }}$ & shoot & root & shoot & root & shoot \\
\hline Control & \multicolumn{2}{|c|}{$0.68 \pm 0.003$} & $0.8 \pm 0.005$ & $0.93 \pm 0.002$ & $1.14 \pm 0.003$ & $1.12 \pm 0.002$ & $1.4 \pm 0.001$ \\
\hline TC1 & \multicolumn{2}{|c|}{$6.56 \pm 0.003$} & $7.9 \pm 0.02$ & $8.25 \pm 0.002$ & $10.5 \pm 0.02$ & $9.35 \pm 0.003$ & $12.1 \pm 0.01$ \\
\hline TC2 & \multicolumn{2}{|c|}{$15.3 \pm 0.003$} & $19.4 \pm 0.002$ & $19.07 \pm 0.001$ & $25.07 \pm 0.003$ & $17.1 \pm 0.002$ & $22.8 \pm 0.001$ \\
\hline TC3 & \multicolumn{2}{|c|}{$24.1 \pm 0.002$} & $37.8 \pm 0.01$ & $30.52 \pm 0.01$ & $41.25 \pm 0.005$ & $32.14 \pm 0.008$ & $43.9 \pm 0.006$ \\
\hline TC4 & \multicolumn{2}{|c|}{$28.9 \pm 0.002$} & $41.04 \pm 0.008$ & $34.1 \pm 0.004$ & $45.5 \pm 0.008$ & $36.2 \pm 0.006$ & $48.62 \pm 0.006$ \\
\hline
\end{tabular}

Results are means \pm SE $(n=3)$ 
Table 2: Chromium up take with varying cadmium concentrations on different harvest days

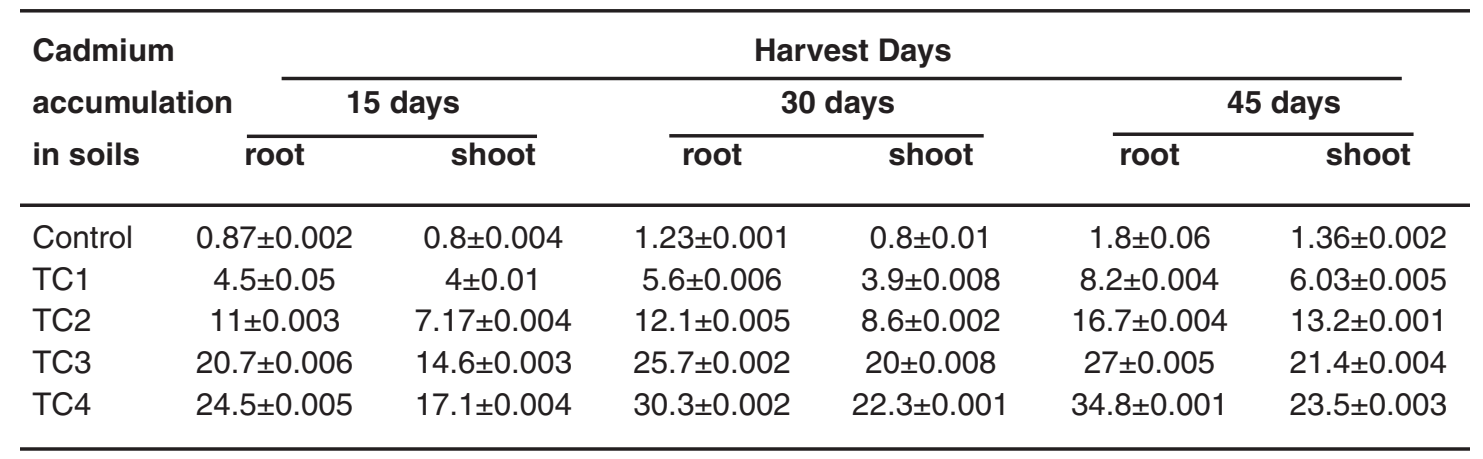

Results are means \pm SE $(n=3)$

Table 3: BCF \& TF in cadmium \& chromium

\begin{tabular}{|c|c|c|c|c|c|c|}
\hline \multirow{3}{*}{$\begin{array}{l}\text { Metal } \\
\text { Accumulation }\end{array}$} & \multicolumn{6}{|c|}{45 days } \\
\hline & \multicolumn{3}{|c|}{ Cadmium } & \multicolumn{3}{|c|}{ Chromium } \\
\hline & BCF of shoot & BCF of root & $\overline{\text { TF }}$ & BCF of shoot & BCF of root & TF \\
\hline Control & 1.6 & 1.28 & 1.25 & 1.36 & 1.8 & 0.76 \\
\hline TC1 & 1.76 & 1.36 & 1.29 & 1.47 & 2 & 0.74 \\
\hline TC2 & 1.92 & 1.44 & 1.33 & 1.53 & 1.94 & 0.79 \\
\hline TC3 & 2.08 & 1.52 & 1.37 & 1.3 & 1.65 & 0.79 \\
\hline TC4 & 2.15 & 1.6 & 1.34 & 1.68 & 2.08 & 0.81 \\
\hline
\end{tabular}

Results are means \pm SE $(n=3)$

values of cadmium and chromium uptake by plants increased with increased metal concentrations in soils which is in agreement with earlier studies (20). The maximum uptake was observed in cadmium in TC4 on day 45 in both shoot and root $(48.6 \mathrm{mg} / \mathrm{g} \&$ $36.2 \mathrm{mg} / \mathrm{g}$ ). The results of chemical analysis proved that both BCF and TF values are greater than 1.0 in cadmium. Whereas in chromium BCF values are greater than1.0 but TF values are lower than 1.0. Hence, it can be concluded that the test plant species Mirabilis jalapa could be good hyper accumulator for cadmium rather than chromium. However being BCF values greater than 1.0 it can be considered as good for phytostabilizaton of metals. As Mirabilis jalapa is widely distributed, reproduced easily by its seed having strong ecological adaptability and great potential for remediation, it can be highly considered as hyper accumulator for cadmium contaminated soils.

\section{ACKNOWLEDGEMENTS}

Author S.A. Shahanaz begum thanks the University Grants Commission (UGC), New Delhi, India for the financial assistance through Maulana Azad National Fellowship under which the present work was carried out. 


\section{REFERENCES}

1. Nriagu, J.O., Global inventory of natural and anthropogenic emissions of trace metals to the Atmosphere. Nature, 279: 409-411 (1979).

2. Gosh S., "Wetland machromiumophytes as toxic metal accumulators", International Journal of Environmental Sciences, 1 (4), pp 523-528 (2010).

3. Rahimi B, Nejatkhah M P Availability, Accumulation and Elimination of Cadmium by Artemia Urmiana in Different Salinities. J. Biol. Environ. Sci. 4(12):149-157(2010).

4. Alloway, B.J and D.C. Ayres,. Chemical Principles of Environmental Pollution, 2nd Edition, Blackie Academic and Professional, Chapman \& Hall, London (1997).

5. Mangkoedihardjo S, and Surahmaida A Jatropha curcas L. for Phytoremediation of Lead and Cadmium Polluted Soil.World Applied Sciences Journal.4(4): 519-522 (2008).

6. Schnoor, J.L. and S.C. McCutcheon, Phytoremediation Transformation and Control of Contaminants, Wiley-Interscience Inc, USA (2003).

7. Hartman, W.J. Jr., An evaluation of land treatment of municipal wastewater and physical siting of facility installations. Washington, DC; US Department of Army (1975).

8. Mojiri A The potential of corn (Zea mays) for phytoremediation soil Contaminated with Cadmium And Lead. Journal of Biological \& Environmental Science. 5(13): 22-17 (2011).

9. X. Xiao, S.L. Luo, G.M. Zeng, W.Z. Wei, Y. Wan, L. Chen, H.J. Guo, Z. Cao,L.X. Yang, J.L. Chen, Q. Xi, Biosorption of cadmium by endophytic fungus (EF) Microsphaeropsis sp. LSE10 isolated from cadmium hyper accumulator Solanum nigrum L., Bioresour. Technol. 101: 1668-1674 (2010).

10. Gosh M., and Singh S.P., "A review on phytoremediation of heavy metals and utilization of its Byproducts", Applied Ecology and Environmental Research, 3(1), pp.18 (2005).

11. Garbisu C, Herna' ndez-Allica J, Barrutia O, Alkorta I \&Becerril JM Phytoremediation: A technology using green plants to remove contaminants from polluted areas. Rev. Environ. Health 17: 75-90 (2002).

12. Zhuang XL., Chen J., Shim H., Bai Z., New advances in plant growth promoting rhizobacteria for bioremediation, Environmental Interational, 33,pp 406-413 (2007).

13. Stewart, E.A., Grimshaw, M., Parkinson, J.A. and Quarmby, C. In Chemical Analysis of ecological Materials. Blackwell Scientific Publications, Osney Mead, Oxford. P.1-234 (1974).

14. Zayed, A., Gowthaman, S., Terry, N. Phytoaccumulation of trace elements by wetland plants: I. Duckweed. - Journal of Environmental Quality 27: 715-721 (1998).

15. Cui S., Zhou Q., Chao L., Potential hyper accumulation of $\mathrm{Pb}, \mathrm{Zn}, \mathrm{Cu}$ and Cadmium in endurant plants distributed in an old smeltery, northeast China. Environmental Geology, 51, pp 1043-1048 (2007).

16. Raskin, L. Ensley, B.D. Phytoremediation of toxic metals using plants to clean up the environment. John Wiley and Sons Incorporation, New York (2000).

17. Prasad, M. N.V., Stralka, K. Impact of heavy metals on photosynthesis. In Heavy metal stress in plants: From molecules to ecosystems (ed.,). M.N.V. Prasad and J. Hagemeyer, Springer-Verlag. Berlin, Heidelberg, New York. P. 117-128(1999).

18. Fargašová, A., nPastierová, J., \& Svetková, K. Effect of Se-metal pair combinations (Cadmium, Zn, Cu, Pb) on photosynthetic pigments production and metal accumulation in Sinapis alba L. Seedlings Plant

Soil Environ, 52(1), 8-15(2006).

19. Ghosh, M and Singh.S.P. Comparative uptake and phytoextraction study of soil induced chromium by accumulator and high 
biomass weed species. - Applied Ecology and Environmental Research 3(2): 67- 79 (2005).

20. YuoHong Su, Youn-Guan Zhu Influence of lead on attrazine uptake by rice (Oryza Sativa L.) seedlings from nutrient solution. - Environmental Science and Pollution Research 12(1): 21-27 (2005). 